\title{
MERCADO DOS PRODUTOS FLORESTAIS NÃO-MADEIREIROS DO CERRADO BRASILEIRO
}

\author{
MARKET OF NON-WOOD FOREST PRODUCTS FROM BRAZILIAN SAVANNA
}

\author{
Sandra Regina Afonso ${ }^{1}$ Humberto Ângelo ${ }^{2}$ \\ RESUMO
}

Este trabalho traz uma análise da produção de não-madeireiros do cerrado brasileiro por meio do estudo dos principais produtos do bioma. Foram analisados o comportamento e as taxas de crescimento da produção e preços de: amêndoa de babaçu, óleo de copaíba, fibra de buriti, folha de jaborandi, casca de barbatimão, casca de angico, fruto da mangaba e amêndoa de pequi, durante o período de 1982 a 2005. Todos produtos estudados apresentaram queda na produção, com exceção do óleo de copaíba e da amêndoa de pequi, os quais apresentaram taxas de crescimento positivas: 12,9 e $8,5 \%$ respectivamente. A análise dos preços foi dificultada pela diversas variações da moeda brasileira no período, apenas as cascas de barbatimão e angico e a amêndoa de pequi apresentaram tendências significativas, sendo positivas: 10,9, 6,7 e 4,6\% respectivamente. Desse estudo, concluiu-se que embora o óleo de copaíba tenha apresentado maior aumento na produção sua oferta provém em quase sua totalidade da região amazônica, assim o pequi se destacou como o principal produto do cerrado.

Palavras-chave: mercado; produtos florestais não-madeireiros; cerrado.

\section{ABSTRACT}

In this article, we analyze the main non-wood forest products from Brazilian savanna. We studied the behavior and the growth rates of production and prices of almond of babaçu, oil of copaiba, fiber of buriti, leaf of jaborandi, bark of barbatimão, bark of angico, fruit of mangaba, almonds of pequi, from 1982 to 2005. All the products exhibited decreasing production, with exception of the oil of copaiba and almonds of pequi, which showed positive growth rates: $12.9 \%$ and $8.5 \%$, respectively. The analysis of prices for most products was not significant, except for barks of barbatimão and angico, and almonds of pequi, which showed positive trends: $10.9 \%, 6.7 \%$, and $4.6 \%$, respectively. We believe that results were not significant due to the severe variations of the Brazilian currency in the period. We conclude that pequi is the main product from savanna and that oil of copaiba has the biggest increase in the production because most of the production comes from the whole Brazilian Amazon region.

Keywords: market; non-wood forest products; Brazilian savanna.

\section{INTRODUÇÃO}

Nas últimas décadas, vários trabalhos analisaram a produção de não-madeireiros a luz de aspectos: econômico, ambiental e social (WICKENS, 1991; BOXALL et al., 2003; SANTOS et al., 2003; ENDERS, 2006; SCHMIDT et al., 2007). Tais trabalhos, contribuem para o entendimento das limitações e oportunidades econômicas dos produtos florestais não-madeireiros como opções de emprego e renda das comunidades e da conservação dos recursos naturais.

Em todo o mundo, as áreas florestadas representam grande valor em razão de seus produtos e serviços. A valorização dos recursos florestais restrita à produção madeireira vem sendo modificada dentro de um contexto macroeconômico, tornando-se cada vez mais evidente a importância de outros produtos e benefícios (SANTOS et al., 2003).

Nesse contexto, os produtos florestais não-madeireiros (PFNMs) são importantes elementos dos recursos florestais em todo mundo (WICKENS, 1991). Definidos como: "menores", "secundários" e "nontimber", os PFNMs surgiram para exprimir o vasto aparato de produtos, animais e vegetais, que não se refiram à madeira derivada das espécies arbóreas da floresta (SANTOS et al., 2003 ).

Milhões de pessoas residentes nas áreas rurais satisfazem uma considerável parte de suas necessidades básicas e renda a partir da colheita de PFNMs (ENDERS et al. 2006). Esses produtos cumprem um papel crucial na vida diária de populações tradicionais, como fonte de importantes insumos, tais como:

1. Engenheira Agrônoma, Doutoranda da Universidade de Brasília, Departamento de Engenharia Florestal, Caixa Postal 04357, CEP: 70919-970, Brasília, (DF). afonsandra@gmail.com

2. Engenheiro Florestal, Dr. Professor do Departamento de Engenharia Florestal, Universidade de Brasília, Caixa Postal 04357, CEP: 70919-970, Brasília (DF). humb@unb.br

Recebido para publicação em 3/04/2008 e aceito em 26/05/2009. 
alimentos, remédios, forragem, fertilizantes, energia, fibra, resina, goma, materiais de construção, entre outros (CASTELLANI, 2002; SANTOS et al., 2003).

Para os povos aborígenes em comunidades rurais ou remotas no Canadá os PFNMs são os motores potenciais para o desenvolvimento econômico (BOXALL et al., 2003). Na Amazônia Brasileira, como em outras matas tropicais, a população local extrai uma grande diversidade de PFNMs para consumo próprio e como matéria prima de indústria artesanal, embora pouco seja reconhecida sua importância (MAY, 1991).

De forma geral, esses produtos são cada vez mais evidenciados não só pelo seu uso nas comunidades, bem como em razão de seu valor comercial. Conforme Igbal (1993 apud ENDERS et al., 2006) existem cerca de 4 mil espécies de PFNMs utilizados com finalidades comerciais. Complementar a importância dos PFNMs para a segurança alimentar das comunidades e para a geração de renda, a utilização de recursos florestais de maneira sustentável é uma importante ferramenta para a conservação dos recursos naturais e das comunidades rurais (DUARTE, 2002; CARVALHO, 2006; EMBRAPA, 2007).

O uso sustentável da biodiversidade do Cerrado pode ser ainda melhor aproveitado para a conservação dos recursos naturais, como a água, os solos e a própria biodiversidade, uma vez que a valorização dessa biodiversidade constitui-se em um forte motivo para preservá-la. Experiências desenvolvidas no cerrado ao norte de Minas e sul do Maranhão, geram renda e conservação ambiental a partir do aproveitamento das espécies nativas (CARVALHO, 2006).

Em Jalapão, estado de Tocantins, a produção de artesanato partindo do capim dourado é uma importante fonte de renda na região desde os anos 90, sendo que a colheita não tem afetado de maneira consistente a densidade populacional, a sobrevivência ou a reprodução das plantas por ano (SCHMIDT et al., 2007).

Para Primack e Rodrigues, 2001, os projetos integrados de conservação e desenvolvimento são citados como as melhores estratégias de conservação desde que se atente para importância de se desenvolver produtos que possam ser extraídos e vendidos a bom preço no mercado.

Assim, para se efetivar tais ações, se torna fundamental a compreensão do mercado consumidor para o direcionamento da coleta e processamento destes produtos. Santos et al., 2003, consideram urgente um maior detalhamento da importância sócio-econômica dos PFNMs bem como sobre o seu mercado.

Conforme Balzon et al. (2004), há um crescente interesse do mercado nacional por PFNMs, influenciado pelo mercado internacional. Contudo as informações de mercado para esses produtos são relativamente escassas. Os produtores, especialmente os de base familiar dispõem de poucas análises de mercado capazes de contribuir na comercialização dos PFNMs (PIRES et al., 1999).

O objetivo deste trabalho é o estudo de mercado dos produtos florestais não-madeireiros do cerrado brasileiro por meio de uma abordagem quantitativa, com ênfase nos principais produtos desse bioma.

\section{MATERIAL E MÉTODOS}

\section{Produtos}

Para análise dos não-madeireiros do cerrado brasileiro estudou-se: a amêndoa de babaçu, o óleo de copaíba, a fibra de buriti, a folha de jaborandi, a casca de barbatimão, a casca de angico, o fruto da mangaba e a amêndoa de pequi. $O$ critério de escolha dos produtos foram: a ocorrência do produto extrativo no cerrado e a presença de dados anuais no período de estudo.

\section{Fonte de dados}

Para a análise, utilizou-se dados obtidos a partir dos Anuários Estatísticos do IBGE e do Sistema IBGE de Recuperação Automática - SIDRA no período de 1982 a 2005. O período de estudo determinou-se pela dificuldade de obtenção de dados anteriores ao ano de 1982 e por se considerar suficiente um série acima de 20 anos de análise.

\section{Variáveis}

As variáveis escolhidas para o estudo foram: a) quantidade da produção brasileira anual dos não-madeireiros em toneladas e b) o preço médio dos produtos não-madeireiros em dólares/tonelada.

A variável preço dos produtos foi obtida a partir da quantidade e valor monetário da produção brasileira anual de cada produto no período de 1982 a 2005. 


$$
\mathrm{P}=\mathrm{V} / \mathrm{Q}
$$
produzida.

Em que: $\mathrm{P}=$ preço em moeda brasileira; $\mathrm{V}=$ valor anual da produção; $\mathrm{Q}=$ quantidade anual

Os valores obtidos para os preços em moeda nacional foram posteriormente transformados para o dólar americano, partindo da média obtida dos valores de compra fornecidos pelo Banco Central do Brasil. Esses ajustes permitiram que os resultados expressassem o comportamento dos preços no período de estudo.

\section{Análise do comportamento e tendências}

Para verificação do comportamento da produção e preços dos produtos, foram elaborados gráficos de produção e preço no período de 1982 a 2005. Para compreender o comportamento observado na produção nacional foi necessário recorrer a análise da produção nos estados fornecedores. Nesse estudo, o período de análise foi de 1990 a 2005, quando se encontraram dados disponíveis no SIDRA.

Para a análise das tendências de produção e preços apresentadas no período de 1982 a 2005 foi utilzado o método de Gujarati (2000), aplicado por Angelo (2001) e Brasil (2002), na qual a tendência linear de uma variável pode ser ajustada pelo método dos Mínimos Quadrados Ordinários - MQO na forma funcional semilogarítimica, conforme as equações [2] e [3].

$$
\begin{aligned}
& \ln P=\beta_{0}+\beta_{\mathrm{p}} \mathrm{T} \\
& \ln \mathrm{Q}=\beta_{0}+\beta_{\mathrm{q}} \mathrm{T}
\end{aligned}
$$

Em que: $\mathrm{P}=$ preço do produto no ano; $\mathrm{Q}=$ quantidade produzida; $\mathrm{T}=$ variável tendência em ano; $\beta_{0}$, $\beta_{\mathrm{p}}$ e $\beta_{\mathrm{q}}=$ parâmetros a serem estimados.

Os coeficientes $\beta_{\mathrm{p}}$ e $\beta_{\mathrm{q}}$ medem a variação relativa constante para uma dada variação absoluta no valor do regressor T (BRASIL, 2002). Neste estudo, os coeficientes $\beta_{\mathrm{p}}$ e $\beta_{\mathrm{q}}$ foram considerados significativos para o nível de significância de 0,01 .

\section{Cálculo das Taxas de Crescimento}

A partir dos parâmetros das tendências $(\mathrm{T})$, obtiveram-se as taxas anuais médias de crescimento $(r)$ conforme aplicado por Brandt (1980), Angelo (2001), Brasil (2002) e Noce et al. (2005).

$$
\begin{aligned}
& r_{\mathrm{p}}=\left(\operatorname{antiln} \beta_{\mathrm{p}}-1\right) * 100 \\
& r_{\mathrm{q}}=\left(\operatorname{antiln} \beta_{\mathrm{q}}-1\right) * 100
\end{aligned}
$$

Em que: $r_{\mathrm{p}}$ taxa de crescimento de preços; $r_{\mathrm{q}}=$ taxa de crescimento da produção.

\section{RESULTADOS E DISCUSSÃO}

\section{Comportamento da Produção}

O comportamento da produção dos não-madeireiros ocorrentes no cerrado pode ser observada na Figura 1. De forma geral, os produtos estudados apresentaram queda na produção, com exceção do óleo de copaíba e da amêndoa do pequi que demonstram produção crescente.

Para a amêndoa do babaçu, foi observada uma queda na produção durante o período de estudo. Essa redução, ocorreu em virtude de mudança de consumo de ambos os óleos extraídos da amêndoa do babaçu, o comestível e o industrial (láurico).

Para o óleo comestível, ocorreu a substituição por óleos mais acessíveis e com gorduras não saturadas, sendo o óleo de soja o principal substituto. (PICK, 1985 apud TEIXEIRA, 2003; HERRMANN et al., 2001). O óleo láurico então se constitui como o principal mercado para o babaçu, tendo o óleo de palmiste e o óleo de côco como seus principais concorrentes (HERRMANN et al., 2001). 

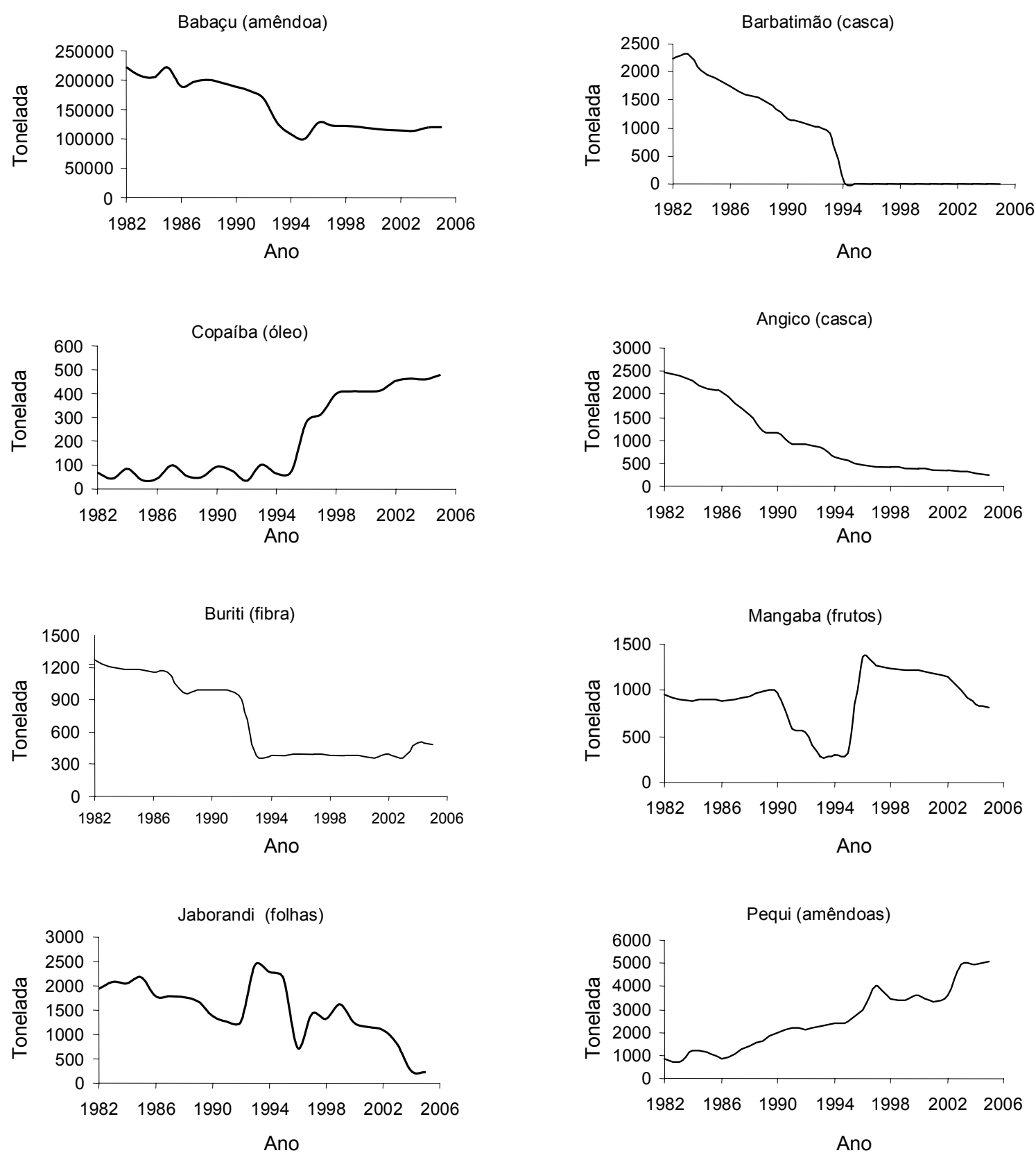

FIGURA 1: Quantidades produzidas em toneladas no período de 1982 a 2005.

FIGURE 1: Quantity of non-wood forest products produced from 1982 to 2005, in tons.

A partir do final da década de 80 e do início da década de 90 a produção apresenta ainda maior queda, conforme os dados do IBGE analisados. A produção brasileira em 1990, superior a 188 mil toneladas de amêndoas de babaçu, reduziu a 99 mil toneladas em 1995.

Ao analisar os cinco principais estados produtores: Maranhão, Tocantins, Piauí, Ceará e Bahia, observa-se o primeiro como o principal produtor. O estado do Maranhão, que em 1990 era responsável por cerca de $70 \%$ da produção nacional, fornecendo 132 mil toneladas, passa a produzir apenas 87 mil toneladas em 1995 , representando então $88 \%$ da produção brasileira.

Essa queda abrupta na produção de babaçu está associada à redução e eliminação das alíquotas de importação de óleos de palma e palmiste (ROCHA NETO, 1993 apud HERRMANN et al., 2001). Este óleo, 
similar ao óleo de babaçu, proveniente da Malásia, entrou no mercado brasileiro por meio de uma agressiva campanha de marketing.

Várias indústrias consumidoras dos óleos láuricos, passaram a utilizar o similar importado, que chegava a preços bastante competitivos e com regularidade de oferta, fechando as portas das indústrias processadoras do babaçu.

A partir de 1996, a produção brasileira do óleo de babaçu teve uma nova ascensão, atingindo 127 mil toneladas anuais, tornando-se estável a partir desse ano. Nesse período, novos contratos internacionais são firmados, entre indústrias de cosméticos e às cooperativas produtoras do óleo, impulsionados pelo apelo social e ambiental.

Duas empresas estrangeiras passam a adquirir óleo bruto e sabonete de babaçu de organizações comunitárias do Maranhão. No final da década de 90, a Cooperativa dos Pequenos Produtores Agrícolas de Lago do Junco (COPPALJ) embarcou cerca de 40 toneladas de óleo bruto para a empresa inglesa The Body Shop para a confecção de loções e batons. Além do óleo bruto, o sabonete fabricado pela Associação das Mulheres Trabalhadoras Rurais (AMTR) também tem sido comercializado. Em 1998, essa Associação embarcou 36 mil sabonetes para a empresa norte-americana Pacific Sensuals Inc., sediada na Califórnia (HERRMANN et al., 2001).

O óleo de copaíba apresentou aumento na produção a partir de 1994, sendo que em 1996 quadriplica a quantidade produzida em relação ao ano anterior. Ao analisar a produção nos cinco principais estados, nos últimos 16 anos, observa-se o estado do Amazonas como detentor de mais de $90 \%$ da produção nacional. Rondônia, Acre, Pará e Mato Grosso são responsáveis pelo restante da produção. Esses dados demonstram que embora a copaíba seja de ocorrência no cerrado, a região amazônica é a principal produtora do seu óleo.

A fibra de buriti, vem apresentando queda na produção nacional até 2003 refletindo a dimunição de oferta pelo estado do Pará, responsável por $76 \%$ da produção brasileira até esse período. Contudo em 2004 há entrada no mercado da fibra de buriti proveniente do estado do Maranhão que passa a fornecer acima de 5 vezes mais, de 26 toneladas para 147, quase $30 \%$ da produção nacional. Esse aumento sugere uma maior aceitação do mercado por produtos gerados partindo da fibra.

A fibra de buriti tem o capim dourado como um produto complementar, pois é utilizada na costura dos fios. Até o momento, não existem dados nacionais para a produção de artesanato partindo do capim dourado, contudo trabalhos realizados por Schmidt et al. (2007) no Tocantins demonstram aumento na extração e venda referente a esse produto.

Os dados do IBGE mostram que a produção nacional de jaborandi dobrou em $1993(2.422 \mathrm{t}) \mathrm{em}$ relação ao ano anterior $(1.257 \mathrm{t})$. Analisando as produções estaduais a partir do início da década de 90 , observa-se o Maranhão como o principal produtor, com mais de $90 \%$ da produção total do País. O Pará apresenta aumento e queda na produção e os estados do Piauí e Bahia participam timidamente do mercado ao longo da série estudada.

O aumento observado na produção em 1993 é por causa da expansão da produção de folhas de jaborandi provenientes do estado do Pará que passa de 65 t, em 1992, para 520 t e da ampliação da produção do Maranhão em cerca de 50\%.

Estudos realizados por Pinheiro (2002) afirmam que a indústria farmacêutica Merck detentora do monopólio da compra no estado do Maranhão faz em 1993 a primeira colheita das plantas cultivadas. Essa colheita pode ter influenciado bastante nos dados apresentados pelo IBGE já que esse não apresenta dados relativos ao cultivo de jaborandi.

Em 1996, dados do IBGE mostram uma queda na produção maranhense de folhas de jaborandi, de 431 toneladas comparadas às $1.761 \mathrm{t}$ no ano anterior. No ano seguinte, em 1997 a produção apresenta uma nova ascenção porém nunca alcançando patamares anteriormente atingidos. Embora nesse ano o estado do Pará volte a reduzir sua produção, em nível nacional há um incremento do produto.

Em 2003, o IBGE registra uma nova queda na produção maranhense, então reponsável pelo fornecimento de mais de $90 \%$ das folhas de jaborandi do páis. Esse fato, leva a produção brasileira à apenas 212 toneladas. Conforme dados de PINHEIRO (2002) nesse período o mercado mundial da policarpina teve problemas devido ao produto sintético que passa a substituir o natural. 
As cascas de barbatimão e angico apresentaram redução drástica na produção, sendo que o barbatimão aponta valores não expressivos no mercado brasileiro nos últimos 10 anos. Em 1982, o país produziu mais de $2.000 \mathrm{t}$ de cascas de barbatimão, reduzindo para $6 \mathrm{t} \mathrm{em} \mathrm{2005.} \mathrm{A} \mathrm{partir} \mathrm{de} \mathrm{1990,} \mathrm{os} \mathrm{dados} \mathrm{de}$ IBGE mostram apenas o estado de Minas Gerais e Bahia como extrativistas da casca de barbatimão. Minas Gerais detentor de 99\% da produção nacional, em 1994, registra apenas 6 toneladas, comparadas com 907 no ano anterior. A partir de 2004, não há registros para o estado de Minas Gerais, ficando a produção nacional restrita ao estado da Bahia.

Não foram encontradas informações que justificassem essa redução. Contudo, estudos realizados por Borges Filho e Felfili (2003) demonstram que a forma de coleta da casca desta espécie vem sendo feita desordenadamente, sem critério de escolha dos indivíduos, colocando-a sob risco de extinção.

Ao analisar as produções de casca de angico nos estados brasileiros, nos últimos 16 anos, observa-se que mais de $96 \%$ dela é proveniente dos estados do nordeste, sendo a Bahia responsável por metade da produção nacional. Os dados do IBGE não nos permitem distinguir as espécies das quais vem sendo feita a extração, contudo a grande presença nos estados nordestinos evidencia a produção do angico vermelho ocorrente no semi-árido.

Não foram encontradas informações que justificassem a queda na produção nacional de angico, contudo um estudo realizado por Paes et al. (2006) na região do semi-árido cita que a espécie tende ao esgotamento devido à exploração desordenada, a falta de práticas de manejo e políticas de reflorestamento. $\mathrm{O}$ mesmo estudo, afirma que apenas um município da Paraíba consome 200 t, o que está em desacordo com os dados do IBGE, nos quais essa seria praticamente toda a produção nacional, estimada em $235 \mathrm{tem} 2005$.

Conforme dados do IBGE analisados, a mangaba sofre uma queda abrupta de produção a partir de 1991. Observando-se a produção nos principais estados confirmou-se que a queda foi ocasionada pela redução no fornecimento pelo estado da Paraíba, o qual em 1990 era responsável por mais de 50\% da produção nacional, 487 toneladas do fruto. Em 1991 o IBGE registra para este estado apenas 73 toneladas, reduzindo ainda mais a partir desse ano.

Os dados do IBGE registram a Bahia como o segundo maior estado produtor de mangaba, e em 1992, passa a ser o primeiro com 391 toneladas, responsável por $72 \%$ da produção nacional. Contudo, a partir de 1993, reduz sua produção para apenas 163 toneladas. Nesse estado, conforme dados de Smitz et al. (2006) a produção de mangaba concorre com outras atividades como a exploração de outras frutas (manga, caju, coco), artesanato e o turismo.

O aumento na produção observado em 1996 está relacionado a entrada no mercado da mangaba proveniente do estados de Minas Gerais e Sergipe. Esses estados juntos passam a produzir mais de 1000 toneladas do fruto, responsabilizando-se por $82 \%$ da produção nacional.

No período de 1998 a 2004 o IBGE não registra nenhum valor para a produção paraibana, voltando a registrar em 2005, 48 toneladas. Esses dados estão em desacordo com os estudos de Silva Júnior, 2004 o qual afirma que somente a Ceasa de Recife, um dos maiores entrepostos de comercialização do Norte e Nordeste, recebeu, em 2001, 590 toneladas de mangaba, provenientes principalmente da Paraíba e do Rio Grande do Norte. Nesse ano, os dados do IBGE registram apenas a produção de 28 toneladas, do Rio Grande do Norte.

O autor ressalta ainda que os valores apresentados para a cultura são subestimados, em razão da maior parte da produção não atravessar os canais convencionais de comercialização: feiras livres, supermercados e centrais de abastecimento. A fruta é destinada principalmente à industrialização e os registros do volume comercializado para esse fim não estão disponíveis.

O estado de Sergipe a partir de 1996 manteve constante a sua produção, sendo em 2005 responsável por mais de $60 \%$ da produção nacional. Esse estado foi alvo de um estudo realizado por Schmitz et al. (2006) que comparam os modos de produção de mangaba em quatro estados do nordeste. Em Sergipe o extrativismo da mangaba está associado ao do manguezal e as duas atividades se complementam.

Para os autores, o estado de Sergipe quando comparado ao estado da Bahia permite a melhor conservação dos recursos genéticos onde há uma alta densidade de plantas no mesmo espaço e a população conhece e pratica todas as fases do extrativismo, bem como da pós-colheita e comercialização. Ainda, no estado as áreas de mangabeiras são contínuas e homogêneas, facilitando a coleta. 
Em 2002, Sergipe e Minas Gerais são responsáveis por mais de $80 \%$ da produção nacional, contudo em 2003, os dados registram uma queda na produção mineira. Minas Gerais que em 2002 produzia $445 \mathrm{t}$ passa a fornecer apenas $235 \mathrm{t}$ no ano seguinte. Em razão disso, os dados do IBGE mostram a produção brasileira da mangaba em declínio sobretudo no ano de 2004 quando os dados registram para Minas Gerais uma nova queda na produção reduzindo a 5 toneladas no ano.

As amêndoas de pequi (Caryocar brasiliense) se destacaram em relação aos outros produtos de estudo em razão constante aumento na sua produção ao longo da série estudada. Para o período de 1990 à 2005 os dados do IBGE apontaram produção extrativa para o pequi em dez estados brasileiros: Pará, Tocantins, Maranhão, Piauí, Ceará, Pernanbuco, Bahia, Minas Gerais, Mato Grosso e Goiás.

Ao observar as produções de pequi nos estados, sete foram os principais, dentre os quais se destacam Minas Gerais e Ceará. No ano de 1991 foi observado um incremento nacional na produção por causa da entrada no mercado o pequi proveniente do estado do Pará que então se responsabiliza por cerca de $10 \%$ da produção nacional.

No ano de 1996, embora os estados produtores venham apresentando queda na produção os dados, apontam uma produção de $1.333 \mathrm{t}$ de amêndoas de pequi no Ceará, partindo saindo da média de $100 \mathrm{t}$ produzidas até então. $\mathrm{O}$ estado vem aumentando sua produção, chegando a 2.340 t, aproximadamente $45 \%$ da produção nacional em 2005.

Diante desse aumento, os estados de Minas Gerais e Goiás, que anteriormente representavam mais de $60 \%$ da produção nacional de amêndoas de pequi, reduzem a apenas $40 \%$. A produção mineira segue apresentando incremento anual, perfazendo cerca de $30 \%$ da produção nacional em 2005, com 1.559 toneladas.

Estudos realizados por Pozo (1997) indicam que chegam para a comercialização anualmente $8.064 \mathrm{t}$ de pequi "in natura" somente no mercado de Montes Claros, no estado de Minas Gerais. Contudo esses dados, não podem ser comparados aos dados do IBGE que faz a coleta da quantidade produzida de amêndoas, como normalmente elas não são comercializadas.

O estado de Goiás, que em 1990 produzira 850 toneladas reduz sua produção a quase metade, $448 \mathrm{t}$ em 1996. A partir desse ano, a produção continua em queda, chegando a $377 \mathrm{t}$ em 2005, o equivalente a $7,41 \%$ das amêndoas de pequi produzidas no Brasil. Esses dados estão de acordo com outros dados fornecidos pelo IBGE relativos à produção agrícola no estado. Goiás apresenta cerca de $66 \%$ de aumento na produção agrícola de 1996, comparado ao ano anterior.

\section{Comportamento dos preços}

O comportamento dos preços dos produtos estudados pode ser observado na Figura 2. Todos os produtos apresentaram patamares marcantes de preços nos anos de alteração da moeda nacional por causa da limitação de se obter os valores precisos nesses anos. Os anos de alteração ocorreram em 1984, 1986, 1989, 1990, 1993 e finalmente em 1994.

Especialmente no ano de 1993, a taxa de câmbio apresentou uma grande variação e todos os produtos tiveram aumento de preços, com exceção do barbatimão, o qual se deu em 1994. A partir do plano real, em 1994, os produtos passam a apresentar maior estabilidade nos preços.

Para a última década, os produtos tiveram um incremento nos preços a partir de 2003, com exceção do angico e barbatimão. Embora o aumento observado não tenha ultrapassado os seus valores máximos anteriormente atingidos, este fato evidencia, para a década, uma maior valorização desses produtos nestes anos, associado a queda nas produções e aumento de mercado consumidor.

Para os tanantes angico e barbatimão, isso não foi evidenciado, embora tenham em 2004 apresentado altos patamares de preço. Porém, em 2005 sofreram uma nova queda. O aumento observado em 2004, está de acordo com a queda na produção observada ao final da série pela escassez destes recursos, os quais a princípio teriam sido valorizados porém posteriormente substituídos.

Em relação ao preço da tonelada da fibra de buriti, os dados calculados apontam uma duplicação de 2003 para 2004, sendo respectivamente aproximadamente US\$175 e 367, bem como de 2004 para 2005, quando chega a US\$ 749. Conforme anteriormente discutido, o produto vem sendo valorizado no mercado nacional e internacional, a partir da comercialização associada ao capim dourado. 

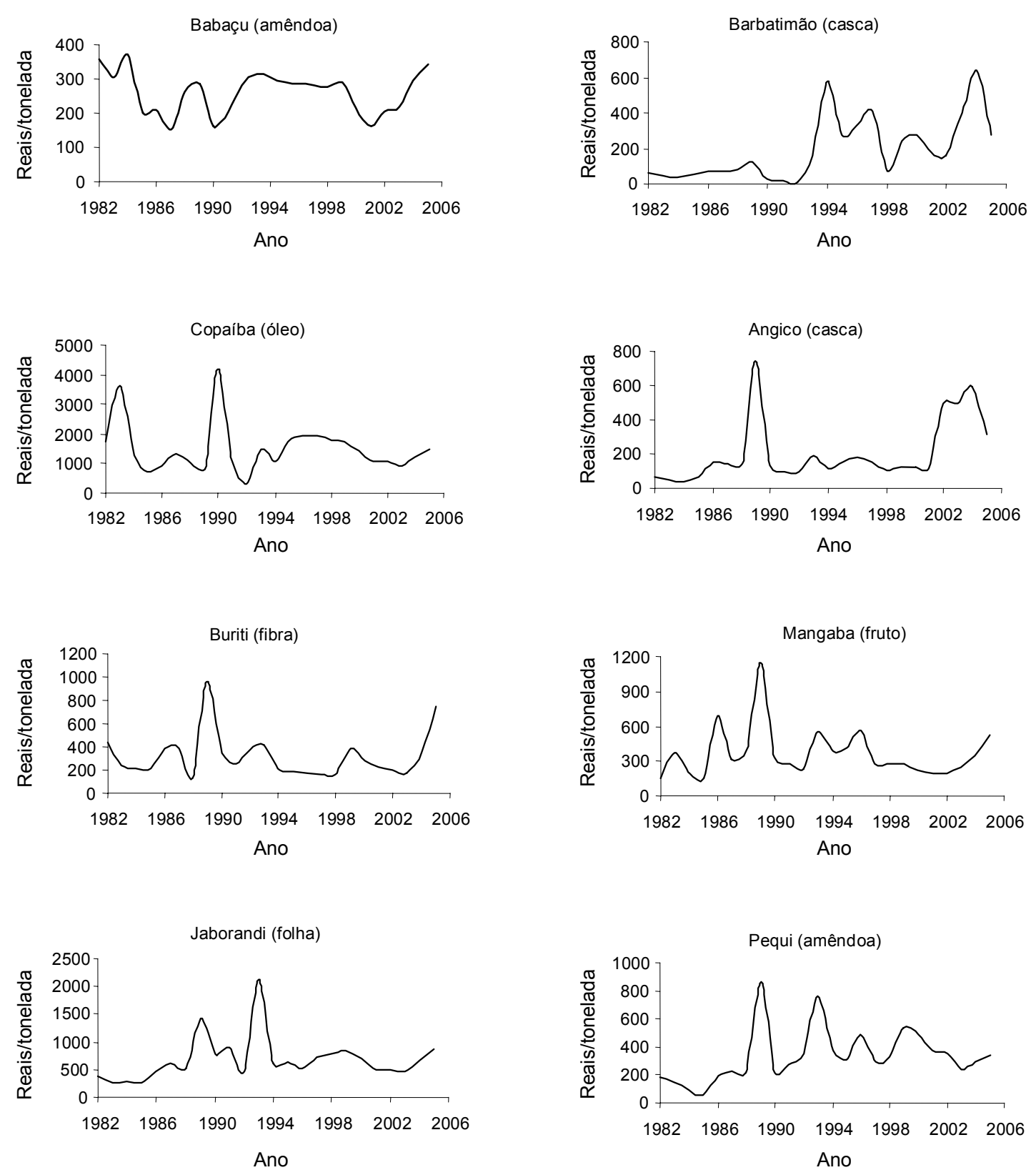

FIGURA 2: Preço dos produtos em dólares por tonelada no período de 1982 a 2005.

FIGURE 2: Price of non-wood forest product from 1982 to 2005, in USD/t.

Dentre os produtos estudados, o óleo de babaçu foi o que apresentou menor instabilidade de preços, associado a equalização com o óleo de palma, proveniente do Pará e de palmiste da Malásia. O preço calculado partindo dos dados de IBGE para a amêndoa de babaçu em 2000 foi de aproximadamente US\$ 216 por tonelada.

Esse valor está de acordo com os estudos de Herrmann et al. (2001), que constataram em maio de 2000, que o preço pago pela amêndoa posta na fábrica em São Luís era de cerca de US\$283,00 por tonelada. Segundo esse estudo os coletores apenas cobrem os custos de estiva e transporte, de forma que a amêndoa funciona apenas como unidade monetária. Contudo o custo para a indústria é significativamente majorado em decorrência da rede de intermediários que se interpõe entre produtores e processadores.

Essa longa cadeia de comercialização, observada no Maranhão, leva a amêndoa de babaçu a apresentar um custo mais alto quando comparada ao preço da amêndoa de palma proveniente do estado do 
Pará. Conforme Herrmann et al. (2001) enquanto a amêndoa de babaçu custa em torno de $\mathrm{R} \$ 0,51 / \mathrm{kg}$, a amêndoa de palma gira em torno de US $\$ 0,16 / \mathrm{kg}$, o que representa cerca de 29 e $17 \%$ do preço final do produto respectivamente.

Apesar do alto custo de originação da amêndoa de babaçu e da concorrência nacional com as amêndoas de palma, novos contratos internacionais firmados no final na década de 90 , entre as indústrias de cosméticos e cooperativas produtoras do óleo, levam ao aumento de preços observados no gráfico nesse período.

Conforme estudo de Herrmann et al. (2001), em 2000 a Cooperativa dos Pequenos Produtores Agrícolas de Lago do Junco (COPPALJ), instalada no estado do Maranhão, entregou para a empresa inglesa The Body Shop 43,2 toneladas de óleo de babaçu ao preço de US\$3.000/t, superior aos preços praticados no mercado, em razão do apelo social e ambiental.

A mesma empresa inglesa vem comprando o óleo da copaíba para uso na fabricação de perfumes, tintas e vernizes (SEBRAE, 1998 apud MAY et al. 2001). O preço calculado com base nos dados de IBGE para esse óleo em 2004 foi de R 3,32 por kilo. Contudo o produto tem uma grande variação de preço no mercado, conforme estudo de Shanley e Medina (2005), o litro varia no estado do Pará de R\$2,00 na compra direta dos coletores a $\mathrm{R} \$ 225,00$ no aeroporto de Belém.

O preço calculado partindo da produção e valor fornecidos pelo IBGE para as folhas de jaborandi são de US\$ 842,78 por tonelada, ou seja US\$ 0,84 por quilo no ano 1997. Esses dados estão em desacordo com os estudos de Pinheiro (2002) que afirma que os compradores no Maranhão estavam pagando entre US\$ 2,50 a 4,00 por quilo de folhas de jaborandi, dependendo da classificação destas.

O comportamento do preço da mangaba apresentou um pico no ano de 1996, além daqueles anteriormente discutidos em razão da mudança de moeda. Ao contrário do que se esperava devido ao aumento na produção constatada para esse ano. Estudos realizados por Silva Junior, 2004 confirmam que o preço do quilo da fruta em 2001, custava em torno de $\mathrm{R} \$ 0,50$ a $\mathrm{R} \$ 1,50$, encontrando valores superiores nos supermercados. Para esse ano, dados calculados a partir dos valores do IBGE estiveram em torno de R $\$ 0,45$.

Em relação ao comportamento do preço da amêndoa de pequi, foram observados dois picos de preços, em 1996 e 1999, além daqueles anteriormente discutidos devido à mudança de moeda. Para o ano de 1996, o trabalho de Pozo (1997) cita o valor da venda do pequi sem casca no mercado de Montes Claros de R\$ 0,50 a 4,00. Considerando que a dúzia de amêndoa equivale a $1,5 \mathrm{~kg}$, os dados do IBGE calculados para o preço no estado de Minas Gerais foi de $\mathrm{R} \$ 0,80 / \mathrm{kg}$, ou seja, $\mathrm{R} \$ 1,20$ para a dúzia.

\section{Tendências e taxas de crescimento da produção e preço}

Para sete dos produtos estudados foram encontrados valores significativos para o paramêtro $\beta$ de produção, considerando o nível de signifância de 0,01 . Apenas a mangaba não apresentou, no período, tendências crescentes ou decrescentes (Tabela 1).

TABELA 1: Análise estatística e estimativa da taxa de crescimento da produção dos produtos florestais não-madeireiro do cerrado $(1982-2005)$.

TABLE 1: Statistic analysis and production growth rates of non-wood forest products from Brazilian savanna $(1982-2005)$.

\begin{tabular}{l|r|r|r|r|r|r}
\hline \multicolumn{1}{c}{ Produto } & \multicolumn{1}{c}{ Produção } & \multicolumn{1}{c}{$\mathrm{F}$} & \multicolumn{1}{c}{$\boldsymbol{r}_{\mathrm{q}(\%)}$} \\
\hline Babaçu & 80,716 & $-0,035$ & 0,780 & $-8,819^{*}$ & 77,783 & $-3,5$ \\
Copaíba & $-238,124$ & 0,122 & 0,756 & $8,263^{*}$ & 68,279 & 12,9 \\
Buriti & 133,687 & $-0,064$ & 0,748 & $-8,087^{*}$ & 65,404 & $-6,2$ \\
Jaborandi & 128,717 & $-0,061$ & 0,486 & $-4,561^{*}$ & 20,806 & $-6,0$ \\
Barbatimão & 665,163 & $-0,326$ & 0,826 & $-10,212^{*}$ & 104,290 & $-27,9$ \\
Angico & 225,049 & $-0,110$ & 0,979 & $-32,241^{*}$ & $1.039,499$ & $-10,5$ \\
Mangaba & $-9,790$ & $-0,008$ & 0,017 & 0,611 & 0,374 & -- \\
Pequi & $-156,593$ & 0,082 & 0,929 & $17,019^{*}$ & 289,663 & 8,5 \\
\hline
\end{tabular}

Em que: * = nível de significância 0,01 . 
Conforme, anteriormente discutido, o pequi e a copaíba apresentaram tendências crescentes na produção e taxas anuais de crescimento positivas, $8,5 \%$ e $12,9 \%$ respectivamente. O babaçu, buriti, jaborandi, barbatimão, e angico mostraram tendências de queda, como taxas de crescimento anuais negativas: $3,5,6,2,6,0$ e $27,9 \%$ respectivamente.

Em relação aos preços dos produtos de estudo, foram encontrados valores significativos para o paramêtro $\beta$, nas séries do pequi, barbatimão e angico, considerando-se o nível de signifância de 0,01 (Tabela 2).

TABELA 2: Análise estatística e estimativa da taxa de crescimento do preço dos produtos florestais não madeireiro do cerrado $(1982-2005)$.

TABLE 2: Statistic analysis and price growth rates of non-wood forest products from Brazilian savanna $(1982-2005)$.

\begin{tabular}{l|r|r|r|r|r|r}
\hline \multicolumn{1}{c}{ Produto } & \multicolumn{1}{c}{ Preços } & \multicolumn{1}{c}{} \\
\hline Babaçu & \multicolumn{1}{c}{$\beta_{0}$} & $\beta_{\mathrm{p}}$ & $\mathrm{R}^{2}$ & $\mathrm{t}$ & $\mathrm{F}$ & $r_{\mathrm{q}(\%)}$ \\
Copaíba & 9,659 & $-0,002$ & 0,0033 & $-0,272$ & 0,074 & - \\
Buriti & 13,631 & $-0,003$ & 0,002 & $-0,206$ & 0,043 & - \\
Jaborandi & 14,860 & $-0,005$ & 0,004 & $-0,313$ & 0,098 & - \\
Barbatimão & $-42,427$ & 0,024 & 0,128 & 1,798 & 3,232 & - \\
Angico & $-202,200$ & 0,104 & 0,461 & $4,338^{* *}$ & 18,815 & 10,9 \\
Mangaba & $-124,374$ & 0,065 & 0,370 & $3,594 * *$ & 12,917 & 6,7 \\
Pequi & 7,568 & $-0,001$ & 0,000 & $-0,061$ & 0,004 & 4,6 \\
\hline
\end{tabular}

Em que: ** = nível de significância $0,01 \%$.

Como era de esperar, o barbatimão e angico apresentaram tendência de aumento nos preços como taxas anuais de crescimento positivas de 10,9 e $6,7 \%$ respectivamente. Isso ocorreu em razão da queda apresentada na oferta desses não-madeireiros o que ocasionou o aumento nos preços.

O pequi, embora tenha apresentado tendência de aumento na produção, demonstrou tendências e taxas de crescimento positivas nos preços, $4,6 \%$, evidenciando a maior valorização do produto. $\mathrm{O}$ aumento na quantidade ofertada e no valor do pequi está associado a crescente utilização das diversas partes do fruto. Da polpa, se faz a extração do óleo para uso alimentício e medicinal, bem como a fabricação de licores. O fruto, adicional a comercilização "in natura" vem também sendo ofertada sua polpa em conserva, bem como é feito o aproveitamento da castanha.

\section{CONCLUSÕES}

Deste estudo, conclui-se que a produção dos principais produtos florestais dos não-madeireiros de ocorrência no cerrado diminuiu durante o período de 1982 à 2005, com exceção do pequi e da copaíba. A copaíba, embora tenha apresentado maior aumento na produção, sua oferta provém em quase sua totalidade da região amazônica, assim o pequi se destacou como o principal produto do cerrado.

A análise mostrou ainda a crescente valorização dos produtos não-madeireiros do cerrado, considerando-se que nos dois últimos anos do estudo observou-se um aumento nos preços de seis dos produtos estudados.

Durante o estudo, observaram-se certas limitações ao analisar as séries temporais nos dados de produção, nas quais se encontraram algumas incoerências quando comparados uns anos com outros. Ao se confrontar os dados do IBGE com as pesquisas realizadas nas áreas extrativas, percebeu-se que esses dados subestimam a produção dos não madeireiros do cerrado. Isso evidenciou o pouco conhecimento a respeito do quanto o extrativismo, enquanto atividade econômica, representa para o país.

Em relação ao comportamento de preços dos produtos, a análise se tornou ainda mais difícil devido à falta de dados relativos aos preços de venda e sim ao valor total da produção. As inúmeras mudanças na moeda brasileira e alta inflação evidenciada no período de 1982 a 1994 também foram fatores limitantes no estudo. 
Apesar das limitações aqui apresentadas, esse estudo traz um cenário temporal inédito sobre o extrativismo no cerrado. Até o momento, diversos trabalhos utilizaram-se desses dados, de forma isolada, relativos ao ano de sua pesquisa ou a série temporal de um só produto.

\section{REFERÊNCIAS BIBLIOGRÁFICAS}

ANGELO, H.; BRASIL, A. A.; SANTOS, J. Madeiras tropicais: análise econômica das principais espécies florestais exportadas. Revista Acta Amazônica, Manaus, v. 31, n. 2, p. 237-248, abr./jun., 2001.

BALZON, D. R.; SILVA, J. C. G. L.; SANTOS, A. J. Aspectos mercadológicos de produtos florestais não-madeireiros - análise retrospectiva. Revista Floresta, Curitiba, v. 34, n. 3, p. 363-371, set./dez., 2003.

BOXALL, P. C.; MURRAY, G.; UNTERSCHULTZ, J. R. Non-timber forest productsfrom the Canadian boreal forest:an exploration of aboriginal opportunities. Journal of Forest Economics, Umeá, v. 9, n. 2, p. 75-96, Aug. 2003.

BORGES FILHO, H. C.; FELFILI, J. M. Avaliação dos níveis de extrativismo da casca do barbatimão [Stryphnodendron adstringens (Mart.) Coville] no Distrito Federal, Brasil. Revista Árvore, Viçosa, v. 27, n. 5, p. 735-745, set./out., 2003.

BRASIL, A A. As exportações de painéis de madeira. 2002. 74 f. Dissertação (Mestrado em Ciências Florestais) Universidade Federal do Paraná, Curitiba.

CARVALHO, I. S. H. Desenvolvimento e gestão ambiental para assentamentos rurais no Cerrado. In: ENCONTRO DA A ASSOCIAÇÃO NACIONAL DE PÓS-GRADUAÇÃO E PESQUISA EM AMBIENTE E SOCIEDADE, 3., 2006, Brasília. Anais... Brasília: ANPPAS, 2006. 1 CD-ROM.

CASTELLANI, D. C. Plantas medicinais e aromáticas: produtos florestais não madeireiros (PFNM). In: SEMINÁRIO MATOGROSSENSE DE ETNOBIOLOGIA E ETNOECOLOGIA; SEMINÁRIO CENTRO-OESTE DE PLANTAS MEDICINAIS, 2., 2002, Cuiabá. Anais... Cuiabá: Universidade Federeal do Mato Grosso - UFMT, 2002. 1 CD-ROM.

DUARTE, L. M. G. Desenvolvimento sustentável: um olhar sobre os cerrados brasileiros. In: DUARTE, L. M. G.; THEODORO, S. H. (Orgs.). Dilemas do cerrado: entre o ecologicamente (in)correto e o socialmente (in)justo. Brasília, Garamond, 2002. 239 p.

EMBRAPA - Empresa Brasileira de Pesquisa Agropercuária. A Embrapa nos biomas brasileiros. Brasília: Embrapa, 2007. 16 p.

ENDERS, B. A.; GORCHOV, D.L.; BERRY, E. J. Sustainbility of a non-timber forest product; effects of alternative leaf harvest practices over 6 years on yield and demografy of the palm Chamaedorea radicalis. Forest Ecology and Management, Amsterdam, v. 234, p. 181-191, Oct. 2006.

GUJARATI, D. N . Econometria básica. 3rd.ed. São Paulo: Makron Books, 2000. 846 p.

HERRMANN, I. et al. Coordenação no SAG do babaçu: exploração racional possível?. In: CONGRESSO INTERNACIONAL DE ECONOMIA E GESTÃO DE NEGÓCIOS AGROALIMENTARES, 3., - FEARP/USP, Outubro de 2001.

MAY, P. H. Building instituions and markets for non-wood forest products from the Brazilian Amazon. Unasylva, Paris, v. 42, n. 165, p. 9-16, Sept, 1991.

MAY, P. H. et al. Compilación y analisis sobre los productos florestales no madereros (PFNM) en el Brasil. Santiago: FAO, 2001. 88 p.

NOCE, R. et al. Análise de risco e retorno do setor florestal: produtos da madeira. Revista Árvore, Viçosa, v. 29, n. 1, p. 77-84, jan./fev., 2005.

PAES, J. B. et al. Avaliação do potencial tanífero de seis espécies florestais de ocorrência no Semi-Árido Brasileiro. Revista Cerne, Lavras, v. 12, n. 3, p. 232-238, jul./set., 2006.

PINHEIRO, C. U. B. Extrativismo, cultivo e privatização do jaborandi (Pilocarpus Microphyllus STAPF EX HOLM.; RUTACEAE) no Maranhão, Brasil. Revista Acta Botanica Brasilica, São Paulo, v. 16, n. 2, p. 141-150, abr.jun., 2002.

POZO, O. V. C. O pequi (Caryocar brasiliense): uma alternativa para o desenvolvimento sustentável do Cerrado no norte de Minas Gerais. 1997. 97 f. Dissertação (Mestrado em Administração Rural) - Universidade Federal de Lavras, Lavras. 
PIRES, M. O. et al. Comercialização de produtos de uso sustentável da biodiversidade do Brasil. Brasília: Programa da Nações Unidas para o Desenvolvimento, 1999. (Cadernos para o Meio Ambiente)

PRIMACK, R. B.; RODRIGUES, E. Biologia da conservação. Londrina: Midiograf, 2001. 328 p.

SANTOS, A. J. et al. Produtos nâo madeireiros: conceituação, classificação, valoração e mercados. Revista Floresta, v. 33, n. 2, p. 215-224, 2003.

SCHMIDT, I. B.; FIGUEIREDO, I. B.; SCARIOT, A . Ethnobotany and effects of haversting on the population ecology of Syngonanthus nitens (Bong.) Ruhland (Eriocaulaceae), a NTFP from Jalapão Region, Central Brazil. Economic Botany, Lancaster, v. 61, n. 1, p. 73-85, Mar. 2007.

SCHMITZ, H.; MOTA, D. M.; SILVA JÚNIOR, J. F. Gestão coletiva de bens comuns e conflito ambiental: o caso das catadoras de mangaba. In: ENCONTRO DA A ASSOCIAÇÃO NACIONAL DE PÓS-GRADUAÇÃO E PESQUISA EM AMBIENTE E SOCIEDADE, 3., 2006, Brasília. Anais... Brasília: ANPPAS, 2006. 1 CD-ROM.

SHANLEY, P.; MEDINA, G. Frutíferas e plantas úteis na vida amazônica. Belém: Centro para Pesquisa Florestal Internacional (CIFOR) e Instituto Homem e Meio Ambiente da Amazônia (IMAZON), 2005. 300 p.

TEIXEIRA, M. A. Uma agenda para o babaçu. Revista Econômica do Nordeste, Fortaleza, v. 34, n. 4, p. 562-575, out./dez., 2003.

WICKENS, G. E. Manegement issues for development of non-timber forest products. Unasylva, Paris, v. 42, n. 165, p. 3-8, Sept. 1991. 